\title{
A convenção do clima e a legislação brasileira pertinente, com ênfase para a legislaçáo ambiental no Amazonas
}

\author{
Terezinha de Jesus SOARES ${ }^{1} \&$ Niro HIGUCHI ${ }^{2}$
}

\begin{abstract}
RESUMO
Este trabalho analisou o desempenho do Brasil no cumprimento das obrigações definidas pela Convenção Quadro das Nações Unidas sobre Mudança do Clima (Art. 4.1), do ponto de vista do Direito Internacional e do Direito Positivo Interno, especialmente as normas de Direito Ambiental. Comparou-se a legislação nacional com as normas oriundas da Convenção e as atividades implementadas pelos organismos nacionais, incluindo políticas e programas ambientais, procurando identificar pontos de convergência e de conflito para indicar o que precisa ser feito e permitir, onde necessário, a adaptação das normas internas à consecução dos objetivos traçados. Pretendeu-se demonstrar como se dá a participação do Amazonas nos compromissos para com as mudanças climáticas e, de acordo com os resultados alcançados, oferecer sugestões à gestão de políticas públicas voltadas para o cumprimento das metas traçadas pela Convenção e assumidas pelo Brasil.
\end{abstract}

PALAVRAS-CHAVE

Convenção do Clima, efeito estufa, Amazônia, Direito Ambiental.

\section{The UN Convention on Climate Change and the pertinent Brazilian legislation with emphasis on the environmental legislation in the State of Amazonas}

\section{ABSTRACT}

This work has analyzed the performance of Brazil in relation to the fulfillment of the obligations defined by the United Nations Framework Convention on Climate Change (Article 4.1), from the point of view of the International Law, Internal Positive Law and especially the rules of Environmental Law. It compared the national legislation with the norms originated from the Convention and the activities implemented by the national organisms, including policies and environmental programs, trying to identify the convergent and conflicting points in order to indicate what has to be done, and to allow, where necessary, norms to accomplish the objective planned. This work aimed to show the Amazonas State commitments in relation to the Convention, and to offer suggestions to the administration of public policies directed to the fulfillment of aims determined by the Convention and undertaken by Brazil.

\section{KEYWORDS}

Climate Convention, greenhouse effect, Amazonia, Environmental Law.

\footnotetext{
*Parte da dissertação da primeira autora, aprovada pela Universidade Federal do Amazonas, como parte dos requisitos para obtenção do título de Mestre em Ciências do Ambiente e Sustentabilidade na Amazônia.

${ }^{1}$ Mestre em Ciências do Ambiente e Sustentabilidade na Amazônia, área de concentração em Política e Gestão Ambiental. Av. Darcy Vargas, 129/903, Parque 10, Manaus-Am-Brasil, Cep 69.050020-(92) 3236.8590.teca_soares@hotmail.com.

${ }_{2}^{2}$ Pesquisador do Instituto Nacional de Pesquisas da Amazônia -Caixa Postal 478, Cep 69011-970, Manaus-Am-Brasil, (92) 3643.1843. niro@inpa.gov.br.
} 


\section{INTRODUÇÃO}

Segundo Simon et al. (1992), as atividades humanas têm provocado significativas mudanças na paisagem terrestre e, mais recentemente, na atmosfera. O uso de combustíveis fósseis e as mudanças no uso da terra liberam gases que se acumulam na atmosfera em quantidades tais que impedem que parte da energia solar retorne ao espaço. Isso potencializa o aquecimento do globo provocando o efeito estufa. Estudos revelam que a temperatura média da superfície terrestre pode aumentar de $1,5^{\circ}$ a $4,5^{\circ} \mathrm{C}$ até o ano 2050 (Mitchel et al., 1990 apud Reis, et al., 1994). O crescente agravamento dessa situação motivou a busca de uma solução de amplitude global, uma vez que todos os países contribuem para a situação e deverão sofrer as conseqüências. Em 1992, durante a Conferência das Naçōes Unidas sobre Meio Ambiente e Desenvolvimento (Rio 92), realizada no Rio de Janeiro, foi adotada a Convenção-Quadro das Naçôes Unidas sobre Mudança do Clima (United Nations Framework Convention on Climate Change - UN-FCCC), na qual os países reconheceram a gravidade da situação e se comprometeram a adotar providências para reduzir os efeitos dessas mudanças. As providências incluíam o compromisso de reduzir até o ano 2000 suas emissões de gás carbônico e outros gases causadores do efeito estufa em quantidade que não ultrapassasse os níveis de 1990.

O Brasil foi o primeiro entre 186 países, além da Comunidade Européia, que até o ano 2001 ratificaram a Convenção. O Brasil também é um país vulnerável aos efeitos da mudança climática e, entre esses efeitos, anunciam-se problemas de várias magnitudes, de alcance local e global. No início das discussóes, na década de 1980, o grau de incertezas a respeito do aquecimento global era considerável. Com o passar do tempo essas incertezas vêm dando lugar a evidências cada vez mais claras de que o aquecimento global está alterando os ecossistemas naturais.

Não há mais que contestar as mudanças, a questão principal agora é a sua magnitude e a velocidade com que elas acontecem. A preocupação maior dos cientistas é com a elevação do nível do mar, provocada pelo aquecimento das águas e o derretimento do gelo nos pólos, que ameaça países em todas as latitudes, mas muito especialmente os países insulares e o litoral de vários outros, entre os quais o litoral brasileiro. Em Pernambuco, pesquisadores já constataram mudanças no nível do mar; o Pará e o Rio de Janeiro também se encontram ameaçados (Muehe et al. 2001). Outro problema catastrófico que se anuncia é a quebra da estrutura da produção de alimentos em decorrência de alteraçôes no regime hidrológico nas áreas de plantio.

A Convenção do Clima prevê obrigaçōes diferenciadas para países desenvolvidos e em desenvolvimento. Em 1997, a Convenção adotou o Protocolo de Quioto estabelecendo metas diferenciadas de redução de emissōes e mecanismos de negociação destinados a agilizar o cumprimento das metas por determinados países.
Este trabalho propôs conferir até que ponto o Brasil vem fazendo sua parte no cumprimento dessas obrigações. A partir da comparação usando métodos de análise quantitativa e qualitativa proposta por Ferrari (1982) e baseada em pesquisa bibliográfica e documental (utilizando documentos oficiais, de imprensa e arquivos públicos) este trabalho verificou a forma como o Brasil vem cumprindo suas obrigações junto à Convenção-Quadro das Nações Unidas sobre a mudança do clima. Aqui não é discutida a existência do efeito estufa, tampouco questionada sua abrangência. Parte-se do pressuposto que, tendo aderido livremente à Convenção, o Brasil reconhece o problema, se compromete a colaborar para sua mitigação e por isso deve agir conforme acordado. A Convenção-Quadro das Nações Unidas sobre Mudança do Clima é um Tratado de Direito Internacional e é sob esta ótica que precisa ser implementada, considerando-se tanto as normas de Direito Internacional, como de Direito Interno, garantidas pela Constituição Federal e pelo conjunto da legislação brasileira, especialmente a legislação ambiental.

O efeito estufa é um fenômeno natural que regula a temperatura da terra. A emissão, acima dos padrões de gases do efeito estufa (GEE), produzidos pela queima de petróleo e pela mudança no uso da terra, pode provocar alteraçōes climáticas globais incalculáveis (FBDS, 1994). A maior contribuição brasileira para o efeito estufa decorre da queima da floresta amazônica, uma vez que a produção energética nacional se faz, basicamente, por hidrelétricas ao invés da queima de petróleo. $\mathrm{O}$ tema é abordado do ponto de vista da legislação brasileira, para verificar os pontos de convergência e aqueles que fazem conflitar a legislação nacional e o cumprimento das obrigaçôes assumidas no âmbito da Convenção. Nesta análise são considerados as pesquisas científicas, as políticas públicas ambientais, os programas e os projetos voltados para o meio ambiente, o uso dos recursos naturais ou que, de outra forma, têm influência nas questóes climáticas e contribuem para o agravamento ou a mitigação do efeito estufa.

Considera-se também a legislação dos estados, incluindo o estado do Amazonas, que mantém 98\% de suas florestas intactas e pretende utilizá-las dentro dos mecanismos criados pelo Protocolo de Quioto. Em síntese, este trabalho situa-se na área de políticas públicas e gestão ambiental, tendo como base de comparação normas e preceitos do direito ambiental. Destina-se a analisar a legislação e o comportamento do Brasil diante das obrigações assumidas junto à Convenção-Quadro das Naçôes Unidas sobre Mudança do Clima. A partir das conclusões sugerem-se atitudes que podem contribuir para agilizar a implementação da Convenção, através do envolvimento da comunidade nacional na discussão da mudança do clima, preparar as populaçóes potencialmente atingidas pelos efeitos dessas mudanças e criar poder de barganha para os representantes brasileiros nas instâncias de negociação da Convenção e do Protocolo de Quioto. 


\section{EFEITO ESTUFA E 0 CLIMA GLOBAL}

Segundo Simon (1992), o efeito estufa decorre da presença de determinados gases na atmosfera, que retêm o calor em torno do globo regulando a temperatura e permitindo que a vida se desenvolva da maneira como a conhecemos. Duas são suas fontes: NATURAL

Resultante da quantidade de produtos químicos lançados na atmosfera pelos vulcóes e pela flutuação na intensidade de luz solar que chega à superfície terrestre e também pelas trocas gasosas entre a biosfera e a atmosfera.

\section{ANTRÓPICA}

Produzida pela queima de combustíveis fósseis (petróleo, gás natural e carvão), produção de cimento e outros produtos e pela mudança no uso do solo (substituição de florestas por pastagens e agricultura).

O efeito estufa é necessário para a manutenção do clima e importante para a vida terrestre no seu todo. Em excesso, no entanto, esses gases formam uma espécie de cobertura espessa demais que retém o calor, aquecendo a superfície da terra além do necessário, produzindo alteraçōes no clima terrestre e causando problemas ambientais e econômicos que atingirão todos os países do globo, especialmente, as zonas costeiras e os pequenos países insulares, pois o resultado mais significativo é o aumento do nível do mar, provocado pelo degelo das calotas polares e pelo aquecimento da água do mar.

Os principais gases do efeito estufa (GEE) são: dióxido de carbono $\left(\mathrm{CO}_{2}\right)$, metano $\left(\mathrm{CH}_{4}\right)$, óxido nitroso $\left(\mathrm{N}_{2} \mathrm{O}\right)$, hidrofluorcarbonos (HFCs), perfluorcarbonos (PFCs) e sulfohexafloreto $\left(\mathrm{SF}_{6}\right)$. Atualmente o $\mathrm{CO}_{2}$ constitui $0,034 \% \mathrm{da}$ atmosfera. Estudos do gelo glacial demonstram que o nível de $\mathrm{CO}_{2}$ durante as eras glaciais chegava, aproximadamente, a 200 ppm, entre os períodos glaciais. Quando a terra esteve quente, esse valor era de 288 ppm. Hoje encontra-se em 350 ppm e aumentando (Simon, 1992). Apenas dois grandes conjuntos de ecossistemas trabalham na absorção desse gás: as florestas em processo de crescimento e os oceanos.

Parte da radiação solar dirigida a terra é absorvida pela superfície terrestre (70\%); a outra parte (30\%) é refletida na forma de calor (FBDS, 1994). Desta, uma parcela se dissipa e retorna ao espaço enquanto outra parcela é impedida de retornar pela barreira de gases que funcionam como uma estufa, absorvendo a radiação infravermelha e propiciando o aquecimento da terra. A ocorrência natural desse processo mantém constante a temperatura em torno de $15^{\circ} \mathrm{C}$. Sem a ocorrência natural do efeito estufa, a temperatura média planeta seria em torno de $18^{\circ} \mathrm{C}$ (Simon, 1992).

A preocupação de cientistas e dirigentes mundiais decorre do fato de que a concentração dos gases de efeito estufa na atmosfera está se intensificando a cada dia, em decorrência das atividades humanas. O estudo sistemático das alterações do clima terrestre data da década de 1950 (Deleage, 1997), quando o cientista Keeling iniciou a medição de $\mathrm{CO}_{2}$ na atmosfera e concluiu pela definição de dois tempos na liberação de carbono: um em torno de 1800 , que corresponde ao aumento da utilização de hulha (carvão) e outro, na segunda metade do século XX, correspondente à aceleração do consumo de combustíveis fósseis pelos países industrializados. As atividades humanas lançam, em média, 25 bilhões de t/ $\mathrm{CO}_{2} /$ ano na atmosfera. Projeções mais recentes indicam que o aquecimento médio do planeta estará em torno de $1,5^{\circ}$ e 4,50 até o ano 2050 (Mitchel et al., 1990, em Reis, et al., 1994).

$\mathrm{Na}$ divisão da responsabilidade pela emissão de $\mathrm{CO}_{2}$ os países ricos ficam com a maior parte $-65 \%$, enquanto os países em desenvolvimento contribuem com 34\%. A questão principal é como diminuir a emissão. A quem cabe essa responsabilidade considerando-se que os países ricos são, historicamente, os principais produtores de GEE e que os países pobres não podem prescindir do processo de desenvolvimento. $\mathrm{Na}$ Convenção do Clima, os países se dividem em dois grupos: Partes do Anexo I países industrializados e Partes-não Anexo I - países em desenvolvimento.

Foi adotado o princípio da eqüidade e da responsabilidade comum, mas diferenciada, pelo qual as partes listadas no Anexo I comprometeram-se a adotar medidas internas com o objetivo de até o ano 2000, retornar suas emissōes aos níveis de 1990. As partes do não-Anexo I não têm o compromisso de reduzir emissões, por entendimento geral de que as emissões estão diretamente relacionadas aos seus processos de desenvolvimento. Todos devem submeter à apreciação da Conferência das Partes COP, documento denominado Comunicação Nacional, em que detalham suas políticas internas e apresentam os Inventários de Emissōes (Art. 4.1.a). As partes do Anexo I devem auxiliar os países em desenvolvimento no cumprimento da Convenção, inclusive facilitando a transferência de tecnologias modernas capazes de reduzir as emissões ou fornecendo recursos financeiros, que os auxiliem no trato da questão (Art.4.2.a).

Durante da Conferência das Partes, no Japão, em 1997, foi adotado o Protocolo de Kyoto, que cria mecanismos destinados a facilitar o cumprimento das obrigaçôes de redução de emissões, pelas partes do Anexo I: Implementação Conjunta, Mecanismos de Desenvolvimento Limpo e Comércio de Emissóes. A discussão do Protocolo de Quioto tem tomado todas as COP até o presente momento, uma vez que os países industrializados relutam em reduzir a emissão de $\mathrm{CO}_{2}$, alegando prejuízos em seus processos econômicos. O Governo Bush anunciou, em 2001, que os Estados Unidos não ratificarão o Protocolo. Mas os outros países reunidos em Marrakesh chegaram a um consenso e o Protocolo deverá ser finalmente ratificado na COP prevista para 2002 (Feldmann, 2001). 


\section{O BRASIL E A CONVENÇÃO DO CLIMA}

O Brasil ratificou a Convenção em 1994 e a promulgou por Decreto Presidencial publicado no Diário Oficial da União em 02/07/1998. Esse processo, de acordo com a Legislação Interna (CF. Art. 5\%.\$2。.) e o Direito Internacional, insere a Convenção no Direito Positivo Brasileiro, para que seja cumprida conforme o acordado.

Para implementar a Convenção o Brasil criou a Coordenadoria de Mudança do Clima, através do Dec. 1.160/1994, no âmbito da Comissão Interministerial para o Desenvolvimento Sustentável - CIDES, revogada em 1997. Em 1999 foi criada a Comissão Interministerial de Mudança Global do Clima - CIMGC, sob a presidência do Ministro da Ciência e Tecnologia e vicepresidência do Ministro do Meio Ambiente, destinada a coordenar "a implementação das ações necessárias ao cumprimento dos compromissos assumidos pelo Brasil por força da Convenção do Clima”.

A Comissão funciona na sede do Ministério da Ciência e Tecnologia - MCT e dispõe de um site (www.mct.gov.br/clima) onde reúne as informações referentes à construção da Comunicação Nacional, fonte principal deste estudo. Em decorrência da falta de recursos financeiros e de recursos humanos qualificados para suas atividades a CIMGC, segundo Miguez (2000), decidiu-se concentrar esforços na elaboração do Inventário Brasileiro de Emissões, deixando para uma segunda fase a elaboração do Plano Nacional de Mitigação, obrigaçōes definidas pela Convenção (Art. 4.1.a \& b). Em decorrência dessa decisão a ampliação de esforços para a pesquisa científica, os estudos de vulnerabilidade e a definição de medidas adequadas à adaptação do país à mudança do clima foram deixadas para uma segunda oportunidade (Miguez, 2000).

$\mathrm{Na}$ construção da Comunicação Nacional, a CIMGC inventariou todas as atividades potencialmente mitigadoras dos GEE, relativas ao setor energético, inclusive as emissões fugitivas de metano; a indústria - cimento, alumínio, química, celulose e papel, uso de sulfohexafluoreto e produção e importação de hidrofluorcarbono. E ainda, o uso de solventes, o setor agropecuário e as emissões de metano provenientes da pecuária e da produção de arroz, da queima de resíduos agrícolas, do uso de fertilizantes e da queima do Cerrado. Das atividades que resultam em mudança no uso da terra e florestas constam, a conversão de florestas em pastagens, a variação de estoques de florestas e outras biomassas lenhosas, o abandono das terras cultivadas e as emissões de metano provenientes de hidrelétricas e gerado na disposição e tratamento de resíduos.

O Programa Nacional do Álcool - Proálcool, os programas de conservação de energia - PROCEL e COMPET, conservação e geração elétrica por biomassa - uso da madeira e da cana-deaçúcar, contribuição da geração hidrelétrica para redução de emissões atmosféricas, energias renováveis, transporte coletivo movido a hidrogênio, reciclagem, programa de desenvolvimento energético de estados e municípios e a indústria siderúrgica a carvão vegetal são medidas antigas, implantadas mesmo antes da assinatura da Convenção do Clima ou em fase de experimento. Nenhum deles foi projetado, desenvolvido ou implantado em consideração à Convenção.

Em termos de pesquisa científica há, em andamento, alguns programas e projetos nacionais e em colaboração com instituiçōes internacionais, mas não se encontraram evidências de vínculo entre estes projetos e as decisóes da CIMGC.

Outra decisão altamente significativa na implantação da Convenção do Clima no Brasil é a decisão da CIMGC de que as atividades de implementação conjunta, previstas no Protocolo de Quioto, possam gerar créditos pelos quais os países desenvolvidos e compensem o descumprimento de suas obrigações na redução do nível atual de GEE em seus territórios (CIMGC, 2001). O conceito de implementação conjunta está definido no Art. 4.2.a, da Convenção, que trata das obrigações das Partes e no Art. 3, do Protocolo de Quioto. De acordo com isso os países industrializados devem liderar a adoção das medidas previstas na Convenção e a implementação conjunta deve se dar entre Partes do Anexo I. Entretanto, os países industrializados, segundo o documento citado, pretendem estabelecer um "regime de créditos" pelo qual, mediante projetos financiados em terceiros países, compensariam o descumprimento das metas livremente assumidas e que deveriam ser alcançadas em seus próprios territórios. Os países em desenvolvimento não têm obrigação de reduzir emissões. Cabe-lhes apenas formular e implementar programas nacionais de mitigação da mudança do clima. O Brasil considera que a proposta dos países desenvolvidos pode introduzir um "elemento de iniqüidade" no combate à mudança do clima, transferindo para os países em desenvolvimento o ônus de adotar medidas de redução das emissões, que são obrigações suas na mitigação do clima e isso pode imobilizar o patrimônio ambiental (florestal) dos países em desenvolvimento (CIMGC, 2001)

Essa posição norteia a discussão nacional sobre a mudança do clima, neste trabalho pontuada em vários discursos do Presidente de República e dos Ministros de C\&T nas COP e em eventos internos ligados ao tema. Também delineia a decisão brasileira quanto à não inclusão da floresta brasileira madura nas negociações do MDL. Uma decisão discutida pelo Governo do Amazonas que, de forma independente, está realizando o "Inventário do Estoque de Carbono no Estado e suas potencialidades no Mecanismo de Desenvolvimento Limpo", destinada à oportuna regulamentação de projetos de implementação conjunta (De Paula, 2001).

No uso da floresta, mais especialmente na mudança no uso do solo da floresta amazônica, consiste a maior contribuição do Brasil para o agravamento do efeito estufa. Salati apud Simon (1992) calcula que o desmatamento na Amazônia responde por 4 a 25\% das emissóes de $\mathrm{CO}_{2}$ em todo o mundo. A cada ano o 
desmatamento gera 1,7 bilhão de tC (Salati, 1994). Dados do Projeto Prodes, do INPE, comprovam que a Amazônia já perdeu $15 \%$ de sua cobertura florestal (Palme, 2000), resultando em prejuízo ambiental e econômico-financeiro. Entretanto, o Governo continua projetando e/ou financiando atividades que potencializam o impacto ambiental negativo sobre a região, inclusive atividades agropecuárias, construção de estradas e implantação de projetos como o Avança Brasil (Menconi, 1999), além da total ausência de infra-estrutura de fiscalização no cumprimento da legislação ambiental e da regulamentação do uso do solo na região.

\section{CONCLUSÃO}

A análise baseada em pesquisa bibliográfica e documental, utilizando documentos oficiais, de imprensa e arquivos públicos, mostra que o Brasil cumpre apenas parte daquilo que foi comprometido junto à Convenção-Quadro das Nações Unidas sobre a mudança do clima. Alguns instrumentos de medida foram aprovados, mas não foram implementados. Leis e Decretos já sancionados não produzem efeitos desejados por conta da falta de controle e fiscalização. Ações como o inventário nacional de emissões já está bem adiantado, mas ainda não foi publicado.

Considerando-se como ponto principal o fator emissão de gases do efeito estufa, há duas situações: 1) o Brasil não tem obrigação de reduzir emissōes e 2) a maior parte das emissōes brasileiras provém da queima de suas florestas.

Nas sessōes da COP, o Brasil tem firmado questão na discussão do MDL reclamando a iniciativa primeira dos países desenvolvidos. Mas essa não parece ser a questão principal. $\mathrm{O}$ Protocolo de Quioto foi criado porque, anos depois de promulgada a Convenção, nada havia sido feito para implementar as atividades de mitigação do clima. Criou-se então um meio que, ao invés de acelerar a tomada de decisão, protelou, pelo artifício da discussão, a "estabilização das concentrações de gases do efeito estufa na atmosfera num nível que impeça uma interferência antrópica perigosa no sistema Climático", como propõe a Convenção (Art. 2). As Partes ganharam seis anos em discussóes e o ambiente perdeu, na mesma proporção, em resultados negativos sobre os vários ecossistemas globais. Enquanto se discute, queima-se petróleo e florestas continuam sendo derrubadas no mundo inteiro.

De tudo que ocorreu até agora nas Conferências das Partes não dá para esperar que os mecanismos do Protocolo de Quioto sejam capazes de resolverem, sozinhos, essa questão. Urge que se tomem medidas realmente capazes de estabilizar as concentrações de GEE. Conclui-se que o Brasil precisa por de lado a discussão dos mecanismos criados pelo Protocolo de Quioto e exigir o cumprimento das obrigações instituídas pela Convenção (Art. 4), pois a mudança do clima não espera o fim das discussões, nem deixa de acontecer. $\mathrm{O}$ negócio do carbono é adicional às obrigaçōes das partes, enquanto a mudança do clima é contínua e a cada dia vem mostrando mais resultados. É inadmissível continuar ignorando as evidências do aquecimento global, noticiadas e comprovadas por cientistas e organismos no mundo inteiro. O Brasil tem posição de liderança na Convenção e há Partes do Anexo I, na dianteira das medidas mitigadoras do efeito estufa. Usar essa liderança e buscar alianças para dar novo rumo às discussões, motivar uma tomada firme de posição, pode ser o caminho a tomar. Protelar essa questão agora pode significar problemas que, no futuro, vão exigir ações muito mais drásticas e maior dispêndio de recursos. É preciso tornar a opiniāo pública favorável à ação responsável em seus países e em termos globais. A discussão precisa de um fato novo.

Observando a situação do lado doméstico: não admitir interferência externa na administração de seus recursos, não concordar em sacrificar seu desenvolvimento enquanto outros países continuam poluindo, não significa permitir que a floresta amazônica continue sendo derrubada, principalmente, sem qualquer critério, perdendo recursos de toda ordem, inclusive econômicos. Protelar a discussão resulta em prejuízo real para o País. O desmatamento deve ser contido, primeiramente, por razões internas, entre as quais o melhor aproveitamento social e econômico da terra, a otimização do valor de mercado dos recursos florestais e a geração de postos de trabalho e renda para as populaçôes dessas áreas. Urge que o Brasil lance mão dos recursos disponíveis para conter o desmatamento. Gestão ambiental, exploração racional dos recursos florestais e pesqueiros, recuperação de áreas degradadas, silvicultura, utilização econômica das terras abandonadas, desenvolvimento de mercados para os recursos da floresta, promoção de produtos ecologicamente corretos e proteção dos recursos hídricos, podem resultar, em médio prazo, em fonte significativa de arrecadação. Só a exploração ilegal da madeira na Amazônia causa prejuízos consideráveis em sonegação, baixo índice de aproveitamento das toras e baixo preço da madeira em decorrência da abundância da oferta. Empresas estrangeiras estão explorando os produtos da floresta. Biodiversidade, animais ameaçados de extinção, contrabando de animais, pesca predatória, biopirataria, são outros problemas que requerem a adoção imediata de medidas de controle e a instalação de infra-estrutura para fiscalização e repressão. Desmatamento controlado fatalmente resultará em menor emissão de GEE.

A legislação ambiental brasileira, no conjunto, é adequada e suficiente à implementação da Convenção, mas se torna ineficaz pela incapacidade dos órgãos em fiscalizar e reprimir a ação criminosa contra os recursos naturais.

Os dados do desmatamento comprovam que a fiscalização não funciona ou é ineficaz. $\mathrm{O}$ Brasil tem leis para regular a exploração dos recursos, mas não investe em infra-estrutura para fiscalizar o cumprimento dessas leis em área que, comprovadamente, necessita de fiscalização. Os recursos aplicados 
no monitoramento via satélite, por exemplo, não encontram correspondente no acompanhamento in loco das autorizaçōes de desmatamento. Para ser eficaz a fiscalização deve chegar antes, impedir que o desmatamento aconteça, inibir a ação criminosa na sua origem. E a ação Ministério Público, deve ser intensificada, conforme dispõe o Código Florestal, a Política Ambiental e a Lei de Crimes Ambientais.

O projeto Avança Brasil no que se refere à Amazônia, deve ser reconsiderado sob a ótica da Convenção do Clima, pois, indiretamente, contribui para aumentar a emissão de gases do efeito estufa, especialmente se concretizada a construção de novas rodovias dentro da floresta.

A ênfase das conclusões sobre o desmatamento, neste trabalho, deve-se ao fato de que a grande contribuição do Brasil para o efeito estufa decorre da mudança no uso do solo. A emissão de GEE pela queima de combustível fóssil no Brasil (65 milhôes de $\mathrm{tC}$ anuais) é menor que a da queima da floresta e significativamente inferior à produção pelos países industrializados. Só os Estados Unidos emitem cerca cinco bilhōes de toneladas, anualmente. Nada disso impede, porém que, na combinação da economia de energia versus a redução na emissão de GEE, o programa do álcool volte a ser discutido. A efetivação dessas medidas pode dar ao Brasil maior poder nas negociaçōes.

Apesar dos projetos que têm potencial para reduzir emissões a implementação interna da Convenção ainda carece de várias atitudes, algumas já discorridas ao longo desse estudo, até em decorrência das dimensões geográficas do País. Sugere-se que o primeiro passo seja concluir e tornar público o Inventário Nacional de Emissōes. A segunda iniciativa seria de ampliar a discussão do tema em áreas e níveis o mais diferenciado possível: das instituições científicas e universitárias, às escolas do ensino fundamental, das grandes empresas e corporaçōes da Avenida Paulista, às pequenas comunidades extrativistas. Pode-se começar reunindo os membros da CIMGC, representantes de diferentes ministérios e os técnicos e pesquisadores de todas as instituições envolvidas na elaboração da Comunicação Nacional. Isso é importante para criar consenso para a implementação da Convenção, entre os diversos órgãos responsáveis pela criação e desenvolvimento de programas e projetos que têm efeitos sobre a mudança do clima.

Há várias instituições pesquisando mudança do clima no Brasil. Uma idéia é reunir os pesquisadores para discutir resultados e propor novos caminhos, assim como suas pesquisas podem ser reunidas em uma publicação dedicada ao tema. Não em livro, mas em revistas de divulgação científica. Isso pode ser proposto à Revista Ciência Hoje, da Sociedade Brasileira para o Progresso da Ciência-SBPC, a exemplo da Eco-Brasil, por ocasião da Rio 92. Um simpósio anual sobre mudanças climáticas no Brasil pode ser proposto dentro da Reunião Anual da SBPC.

As representaçōes empresariais não devem ficar ao largo. $\mathrm{O}$ Conselho Empresarial de Desenvolvimento Sustentável é o foro perfeito para fomentar as discussões em sua área de atuação. Éa discussão que vai orientar a formação da opinião pública e permitir à sociedade de posicionar adequadamente numa possível tomada de decisão.

A discussão precisa sair das salas da CIMGC, dos prédios de Brasília para ganhar foros diferentes e permitir que a comunidade assuma a responsabilidade do processo. O Fórum Brasileiro de Mudanças Climáticas - FMC tem que ganhar agilidade e começar a executar as açôes programadas, entre as quais as Câmaras Temáticas, que ainda não saíram do papel. Essas atividades devem ser implementadas no Brasil todo.

Das obrigações da Convenção além do Inventário e da Comunicação Nacional consta que as Partes devem promover e incentivar a comunicação, a cooperação técnica, o desenvolvimento científico e tecnológico, a adoção de medidas sociais, econômicas e ambientais e a promoção da educação e treinamento destinados a estimular a participação da sociedade, inclusive na busca de soluçôes para os problemas decorrentes da mudança do clima.

O Ministério da Ciência e Tecnologia-MCT, que preside e coordena a CIMGC, dispõe de uma estrutura de comunicação formada por jornalistas, assessores e técnicos lotados em todos os institutos de pesquisa. Esses profissionais estão acostumados a trabalhar com divulgação científica, dispõem de facilidades de trânsito entre pesquisadores e mantêm canais de comunicação com jornalistas. Por seu lado, nos Institutos há vários pesquisadores trabalhando com mudança climática e alguns têm publicaçōes científicas próprias. Essa estrutura pode ser integrada ao processo de implementação da Convenção. O Ministério do Meio Ambiente - MMA, que detém a Vice-presidência da CIMGC, publica o jornal "Protetores da Vida", destinado à divulgação do Programa Nacional de Educação Ambiental, um recurso pronto para ser utilizado. Também deve ser incentivada a ediçāo comercial de livros, revistas e quadrinhos sobre o tema, voltados para as crianças, a exemplo da coleção S.O.S. Planeta Terra.

Em termos locais a iniciativa do Estado do Amazonas, através do Instituto de Proteção Ambiental - IPAAM, na elaboração do Inventário do Estoque de Carbono, inicialmente voltada para o MDL, tem potencial para orientar outras açôes relacionadas com a mudança no uso da terra na região, inclusive a regulamentação fundiária e de manejo florestal. Sendo uma primeira iniciativa poderá vir a ser discutida e melhorada através de outros projetos. Essa iniciativa do IPAAM representa uma ação concreta no cumprimento da Constituição Estadual para "assegurar o equilíbrio ecológico" em sua área de jurisdição. A esperança é que as informações sejam realmente utilizadas para o bem estar de todos e para preservar os recursos naturais desta parte do Brasil para as geraçôes que hão de vir, enquanto orienta iniciativas que efetivamente resultem no cumprimento das obrigaçōes para com a Convenção do Clima e a estabilização da concentração dos gases de efeito estufa. E que sirva de modelo e inspiração para outros Estados dentro e fora da Amazônia. 


\section{REFERÊNCIAS BIBLIOGRÁFICAS}

CIMGC - Comissão Interministerial de Mudança Global do Clima. 2001. Atividades Implementadas Conjuntamente - Posição do Brasil. (http//:www.mct.gov.br/clima).

Deléage, J.P. 1997. Uma ecologia mundo, in Faces do Trópico Úmido: conceitos e questôes sobre Desenvolvimento e Meio Ambiente. Edna Castro e Florence Pinton (org.). Belém: UFPA/NAEA. páginas

De Paula, Estevão M. 2001. Inventário do estoque de carbono no Estado do Amazonas e suas potencialidades para o MDL. Manaus, IPAAM, nov. 2001. Entrevista concedida a Terezinha Soares.

FBDS - Fundação Brasileira para o Desenvolvimento Sustentável. 1994. Efeito Estufa - Um problema que envolve todas as naçôes. Rodrigues, A. (ed.) (s.l.) Bloch Ed. 24 pp.

Feldmann, F.; Macedo, L. V. e Biederman R. 2001. Ficou para Marrakesh ... Último relatório da COP6,5 em julho de 2001 em (http//:www.mct.gov.br/clima).

Ferrari, Alfonso Trujillo. 1982. Metodologia da Pesquisa Científica. São Paulo: MacGraw-hil do Brasil. 318 pp.

Folha de São Paulo. 2001. Bush põe economia dos EUA antes do clima. São Paulo, p. A19, 30/02/01.

Menconi, Darlene. 2001. Até onde ela agüenta? ISTOÉ, São Paulo, n. 1661, p. 64-68, $1^{\circ}$ ago. 2001.

Miguez, J.D. 2000. Sobre a construção do site. (http// :www.mct.gov.br/clima).

Muehe, D. e Neves, C. F. 2001. As implicações do aumento do nível do mar na costa brasileira: Uma avaliação preliminar em (http/ /:www.mct.gov.br/clima).

Reis, M. das G.F.; Reis, G.G.; Valente, O.F. e Fernandes, H.E. de C. 1994. Seqüestro e armazenamento de carbono em florestas nativas e plantadas dos estados de Minas Gerais e Espírito Santo em Seminário Emissão x Seqüestro de $\mathrm{CO}_{2}$. - Rio de Janeiro: Companhia Vale do Rio Doce, p.155-195.
Salati, Eneas. 1994. Emissão x seqüestro de $\mathrm{CO}_{2}$ : uma nova oportunidade de negócios para o Brasil em Seminário Emissão x Seqüestro de $\mathrm{CO}_{2}$. - Rio de Janeiro: CVRD. p. 13-37

Simon, Cheryl e DeFries, Ruth S. 1992. Uma terra, Um Futuro; Traduzido por Maria Cláudia S.R. Ratto; São Paulo: Makron Books. 189 pp.

\section{SILGAS UTILIZADAS}

CIDES - Comissão Interministerial para o Desenvolvimento Sustentável

CIMGC - Comissão Interministerial de Mudança Global do Clima COP - Conferência das Partes

FBDS - Fundação Brasileira para o Desenvolvimento Sustentável

FMC - Fórum Brasileiro de Mudanças Climáticas

GEE - Gases do Efeito Estufa

INPE - Instituto Nacional de Pesquisas Espaciais

IPAAM - Instituto de Proteção Ambiental do Estado do Amazonas

MDL - Mecanismo de Desenvolvimento Limpo

MCT - Ministério da Ciência e Tecnologia

PROÁLCOOL - Programa Nacional do Álcool

UN-FCCC - United Nations Framework Convention on Climate Change

Recebido em 24/08/2005

Aceito em 20/09/2006 
